\title{
FORMAÇÃO DOCENTE E LETRAMENTO: UMA REALIDADE VIVENCIADA NA EJA
}

\author{
Renata da Silva Posso* \\ Isabel Cristina Michelan Azevedo*
}

\begin{abstract}
RESUMO: Este estudo objetiva discutir a formação de professores a partir da utilização de materiais didáticos condizentes com a promoção do letramento social no trabalho pedagógico dentro da sala de aula. Trata-se de uma pesquisa social, apoiada no estudo de caso junto a uma escola pública de Ilhéus/BA, a partir de entrevista com uma professora da EJA, voltada ao entendimento da sua formação profissional e dos modos de escolha, elaboração e utilização do material didático. Como aporte teórico, destaca-se Freire que transita pela educação de jovens e adultos em diferentes frentes, tanto no entendimento deste ambiente desafiador, quanto nas questões relacionadas aos saberes necessários ao professor para uma prática educativa transformadora e emancipatória; Tardif (2004) que aborda os saberes docentes e sua relação com a formação profissional implicados na atividade docente; Street (2015) que propõe os modelos de letramento autônomo e ideológico, com repercussão nas práticas de letramento social para apropriação da leitura e escrita; e Mello (2015), que trata a produção didática da EJA como práticas de produção e construção de saberes no meio escolar. Em síntese, discorrem-se algumas análises da voz da docente visando perscrutar a apropriação de saberes que são determinantes para a profissionalização numa prática didático-pedagógica que possa ressignificar as relações entre língua/linguagem entre os sujeitos que se encontram implicados em situações sociais pertinentes ao ambiente da EJA, a fim de contribuir para a transformação social dos sujeitos envolvidos em processos de ensino e aprendizagem.
\end{abstract}

PALAVRAS-CHAVE: EJA; Formação Docente; Letramento social; Material didático.

\footnotetext{
* Mestranda em Letras: Linguagens e Representações pela Universidade Estadual de Santa Cruz (Uesc). Membro do Grupo de Pesquisa Estudos de Linguagem, Argumentação e Discurso.

** Doutora em Letras pela Universidade de São Paulo (Usp), atualmente trabalha na Universidade Federal de Sergipe (UFS) tanto na graduação quanto na pós-graduação acadêmica (PPGL) e profissional (Profletras) e no Programa de Pós-Graduação em Letras da Universidade Estadual de Santa Cruz (Uesc). É líder do Grupo de Pesquisa em Argumentação e Retórica Aplicadas e do grupo de Estudos em Linguagem, Argumentação e Discurso, ambos com registro no CNPq.
} 


\section{Introdução}

Ao tratar da formação de professores como temática central deste artigo, num primeiro momento, pretende-se colaborar com a superação da "tradicional justaposição entre formação inicial e aperfeiçoamento dos professores" (GARCIA, 1997, p. 55), o que remete à formação de professores como um continuum que interconecta a formação inicial à formação permanente, visando ao desenvolvimento profissional dos professores, tanto em perspectiva pessoal quanto profissional. Isso pressupõe considerar o individual e o coletivo, os aspectos contextuais, organizacionais e orientados que podem proporcionar mudança social (GARCIA, 1997).

Em um segundo momento, a formação de professores é abordada como uma oportunidade para promover a indagação reflexiva, concebida como estratégia de tomada de consciência dos problemas enfrentados na própria profissão docente. A reflexão é entendida como um instrumento favorável à autorreflexão do professor a partir de sua própria prática educativa, a fim de articular pensamento e ação, além de promover a construção de sua identidade pessoal e profissional (GARCIA, 1997).

Como o trabalhador do magistério aprende seu trabalho tanto no contexto familiar quanto social, a aprendizagem de cada um modifica a sua identidade e seus "saberes", por isso notamos que, com o passar do tempo, o trabalho e a aprendizagem, as situações vividas fundamentam os saberes profissionais dos professores, ou seja, os “[...] saberes mobilizados e empregados na prática cotidiana” servirão “[...] para resolver problemas dos professores em exercício, dando sentido às situações de trabalho que lhes são próprias" (TARDIF, 2004, p. 58)

A noção do saber é atribuída por Tardif (2004, p. 60), a "um sentido amplo que engloba os conhecimentos, as competências, as habilidades (ou aptidões) e as atitudes dos docentes". Desta feita, os saberes servem de base para o ensino e estão relacionados com a formação profissional dos professores, partindo do próprio exercício da docência. O saber docente é categorizado em quatro tipos diferentes: os saberes da formação profissional (das 
ciências da educação e da ideologia pedagógica); os saberes disciplinares; os saberes curriculares e, por fim, os saberes experienciais (TARDIF, 2004).

Em um terceiro momento, retomamos a ideia de que a formação docente está associada à prática educativa, por isso o professor, como sujeito produtor de seus saberes, é capaz de mudar a realidade circundante e orientar a construção de conhecimentos dos educandos, sem ficar restrito ao ato de transmitir ou transferir conhecimento (FREIRE, 1997). Freire ressaltou o uso social da leitura e da escrita, questionando os modelos existentes de alfabetização com abordagem "tradicionalista", apoiados no processo de aquisição da leitura e da escrita com base na cultura escolar transmitida ao longo de muitos anos ao educando, e contestou o modelo "bancário"1.

Essa perspectiva alinha-se às reflexões de Brian Street ${ }^{2}(2015$, p. 150) que distingue dois modelos de letramento: o autônomo e o ideológico. Como se sabe há mais de vinte anos, o modelo autônomo pressupõe o ensino para a funcionalidade, a leitura e a escrita são tidas como práticas “neutras”. Em contrapartida, o modelo ideológico propõe o ensino da linguagem para além da funcionalidade, considerando o letramento nos aspectos sociais, culturais e políticos, refere-se ainda às diferentes práticas e aos eventos sociais relacionados às experiências de vida, de leitura e escrita de cada pessoa.

Na educação de jovens e adultos, é relevante destacar o aspecto heterogêneo observado nas turmas de EJA como fator desafiador para o trabalho docente. A diversidade diz respeito a diferentes aspectos: a variação de faixa etária entre jovens, adultos e idosos e os

\footnotetext{
${ }^{1}$ A concepção "bancária" de educação é criticada por Paulo Freire, pois trata a educação como "um ato de depositar, em que os educandos são depositários e o educador o depositantes", nessa perspectiva o educador conduz os educandos à memorização dos conteúdos, fazendo com que a educação seja um "[...]o ato de depositar, de transferir, de transmitir valores e conhecimentos" (FREIRE, 1999b, p. 58).

${ }^{2}$ Os trabalhos de Brian Street resultam de profundas discussões de concepções e modelos de letramento utilizados por vários sujeitos, dentre eles profissionais da educação, instituições, cientistas e políticas públicas. Seus estudos possibilitam o diálogo com a língua portuguesa por contribuir com as discussões sobre letramento como prática social, mediante crítica "sobre os efeitos cognitivos do letramento e da visão dicotômica entre fala e escrita" que reduz o letramento a um conjunto mensurável de capacidades cognitivas (STREET, 2015, p. 9).
} 
diferentes níveis de aprendizado, que decorrem de experiências escolares iniciais e do histórico de múltiplas reprovações na educação formal. Além disso, os estudantes matriculados na EJA trazem consigo diversas experiências pessoais, familiares e sociais, o que exige do professor uma atenção especial no planejamento, na elaboração e utilização dos materiais didáticos, na organização da rotina da sala de aula, na disposição dos alunos no ambiente escolar e na definição de sua prática educativa.

Tendo em vista essas referências teóricas, são propostas as seguintes questões de pesquisa: Como a formação dos professores contribuiu ou dificulta na organização de práticas de letramento voltadas ao grupo heterogêneo de estudantes da EJA? Qual a relevância dos livros didáticos utilizados pelos professores de EJA em Ilhéus no processo de ensinoaprendizagem de língua portuguesa? Que outros materiais didáticos são utilizados pelo professor da EJA? Há alinhamento desses materiais aos modelos de letramento autônomo e ideológico ${ }^{3}$ ?

Em síntese, este artigo objetiva discutir a formação de professores a partir da utilização de materiais didáticos condizentes com a promoção do letramento social no trabalho pedagógico dentro da sala de aula. Também considera as reflexões acerca das possibilidades para o desenvolvimento do letramento dos estudantes por meio de práticas de leitura e escrita, a fim de ampliar a fase de decodificação do sistema de escrita alfabético, considerando as vantagens das atitudes dialógicas que estimulam os estudantes ao aprendizado para que possam responder às necessidades sociais.

\footnotetext{
3 Brian Street (2015) considera o letramento sob dois enfoques: o autônomo e o ideológico. No modelo autônomo, a leitura e a escrita são concebidas como um produto completo em si mesmo, a partir de habilidades individuais desvinculadas de um contexto. Entretanto, o modelo ideológico não deve ser entendido como uma negação ao modelo autônomo, mas que considera as práticas de letramento vinculadas aos aspectos sociais, culturais e de relações de poder.
} 


\section{Percurso metodológico}

No que tange à abordagem metodológica, este estudo se fundamenta na pesquisa social circunscrita a pesquisa de mestrado acadêmico ${ }^{4}$ realizada na Universidade Estadual de Santa Cruz. Assim, busca investigar as práticas do letramento desenvolvidas em situações de uso da linguagem oral e escrita em âmbito social e escolar (GIL, 2008, p. 26), por isso houve a integração direta entre pesquisadores e a professora, que compartilhou suas experiências escolares, bem como o processo de produção e utilização de materiais didáticos. Para tanto, foi obtida a aprovação do Comitê de Ética em Pesquisa (CEP) da UESC, que está ligado à Comissão Nacional de Ética em Pesquisa (CONEP).

Diante do contexto pertinente ao ensino da EJA, com as discussões voltadas a formação docente e o processo de letramento, essa pesquisa se inscreve na Linguística Aplicada Crítica (LAC), pois visa colaborar com as investigações que podem " [...] revelar processos pelos quais a linguagem funciona para manter ou mudar as relações de poder na sociedade" (PENNYCOOK, 2007, p. 40), permeada por questões relativas à linguagem e aprendizagem da língua materna dos estudantes.

Este estudo de caso está apoiado nas experiências realizadas em uma escola pública municipal, no período de março a maio de 2019, situada na periferia da área urbana de Ilhéus, na Bahia, que oferece à população a educação de jovens adultos do primeiro segmento, referente às séries inicias do ensino fundamental, no turno noturno. E está organizada em quatro turmas distribuídas em uma turma da fase I, uma da fase II e duas da fase III. Focamos na turma da fase I, que tem aulas de segunda à sexta-feira, com carga horária semanal de 20 horas, distribuída em três professores das disciplinas de Língua Portuguesa, História, Geografia, Ciências e Matemática 5 .

\footnotetext{
${ }^{4}$ Pesquisa de Mestrado intitulada "As práticas de letramento na educação de jovens e adultos na zona urbana de ilhéus" que objetiva investigar as práticas de letramento vivenciadas nas turmas de Educação de Jovens e Adultos (EJA) das escolas municipais da zona urbana do Município de Ilhéus, na Bahia, vinculada ao Programa de PósGraduação em letras: Linguagens e Representações, da Universidade Estadual de Santa Cruz (UESC).

${ }^{5} \mathrm{~A}$ distribuição da carga horaria de 20 horas semanais por três professores é definida pela escola, sob orientação da Secretaria de Educação (SEDUC), e se justifica pela garantia do período de um terço da carga horária docente para o planejamento, atendendo a Lei do Piso Nacional definida pela Lei $n^{\circ} 11.738$, em 16 de julho de 2008, que 
Com base nos procedimentos técnicos, utilizou-se a entrevista como instrumento para a primeira fase de levantamento de dados, restringindo-se a professora de Língua Portuguesa da turma da fase $\mathrm{I}^{6}$, pois garantindo a inclusão da vOz da professora nos processos de pesquisa, reforçamos a obtenção de resultados que traduzem ainda mais a realidade, evitando que os dados se baseiem "em visões bastante diferentes da subjetividade dos professores" (TARDIF, 2004, p. 234). A entrevista abordou variados tópicos referentes à formação docente, à caraterização da turma, ao planejamento das aulas, às práticas de letramento e à produção e utilização de materiais didáticos.

No viés da pesquisa documental, foram priorizadas as diretrizes norteadoras do Ministério da Educação (MEC) para a Educação de Jovens e Adultos, considerando o âmbito nacional: Proposta Nacional Curricular do $1^{\circ}$ segmento da EJA (2001), e Guia dos Livros Didáticos do PNLD EJA 2014 (2014). Foram cedidos o Diário de Classe ${ }^{7}$, o livro didático (LD) “EJA Moderna: Educação de Jovens e Adultos", volume 1, adotado pela rede municipal de Ilhéus, além o planejamento e as atividades impressas utilizadas pela. Salienta-se que durante o período da investigação de campo, a professora desenvolveu estudos com receitas culinárias.

Todo esse material coletado foi catalogado e analisado, seguindo os seguintes aspectos: formação docente (formação inicial e continuada) voltada às questões pertinentes

instituiu o piso salarial profissional nacional para os profissionais do magistério público da educação básica, garantindo a fixação do vencimento inicial das carreiras do magistério público da educação básica, para a jornada de, no máximo, 40 (quarenta) horas semanais; a elaboração ou adequação de Planos de Carreira e Remuneração do Magistério; e a composição da jornada de trabalho, observar-se-á o limite máximo de $2 / 3$ (dois terços) da carga horária para o desempenho das atividades de interação com os educandos.

${ }^{6}$ Mediante aceitação da professora em participar da pesquisa, com aceite em Termo de Consentimento Livre e Esclarecido (TCLE), foi encaminhada a entrevista focalizada, em ambiente seguro e dentro do ambiente escolar, com gravação em áudio de tudo e seguindo um roteiro previamente definido, que abordou variados tópicos referentes à caraterização da turma, ao planejamento das aulas, às práticas de letramento, à produção e utilização de materiais didáticos e à formação docente, e a coleta de documentos e materiais didáticos, tais como: os livros didáticos, as atividades impressas, as atividades escritas e reproduzidas para os cadernos dos estudantes e os instrumentos de planejamento pedagógico. Garantiu-se a fidedignidade dos dados, bem como o sigilo das informações, conforme as exigências o Processo de Consentimento Livre e Esclarecido.

${ }^{7}$ O Diário de Classe é um documento proposto pela Secretaria de Educação de Ilhéus (SEDUC) para dar suporte à ação pedagógica nas escolas municipais alicerçado no tripé: Planejamento - Ação/Observação - Registro. 
ao domínio de conhecimentos sobre o trabalho com a EJA, o letramento social e a produção do material didático; caracterização da turma, a partir da faixa etária e diferentes aprendizagens; planejamento e trabalho com texto instrucional: receitas culinárias, destacando os motivos para essa escolha e sua pertinência para fase I; atividades elaboradas pela professora, considerando o alinhamento ao letramento social (modelo autônomo ou ideológico), a adequação à realidade dos estudantes, a relação com os motivos que levaram aos estudo sobre receitas e a interface com o livro didático.

É importante destacar que as análises apresentadas a seguir estão fundamentadas em pressupostos teóricos variados. No âmbito das diferentes aprendizagens no ambiente heterogêneo destacamos as reflexões de Oliveira (2004; 2005). Quanto ao letramento, foram considerados as obras de Street (2015). Para tratar da formação de professores recorreu-se ao trabalho de Tardif (2004). Sobre as características dos materiais didáticos para a EJA nos debruçamos nos estudos desenvolvidos por Mello (2015).

\section{Formação de professores}

Iniciamos a discussão sobre formação de professores, a partir da concepção de saberes docentes, apresentada por Tardif (2004), sendo definidos como sendo “[...]um saber plural, formado pelo amálgama, mais ou menos coerente, de saberes oriundos da formação profissional e de saberes disciplinares, curriculares e experienciais" (TARDIF, 2004, p.36).

O saber profissional dos professores, para Tardif (2004), parte das relações existentes entre tempo, trabalho e aprendizagem dos saberes profissionais, servindo como base fundamental para o ensino. Desta feita, essa característica plural e heterogênea da construção dos saberes do professor é proveniente das relações deste com os locais em que atua, com as organizações formadoras e de trabalho, com os instrumentos de trabalho, com sua experiência docente, bem como as diferentes fontes de aquisição destes saberes e com os modos de integração com o trabalho docente, sendo identificado e classificado conforme o Quadro I, apresentado a seguir: 
Quadro 1 - Classificação dos saberes docentes segundo Tardif

\begin{tabular}{|c|c|c|}
\hline $\begin{array}{c}\text { Saberes dos } \\
\text { professores }\end{array}$ & $\begin{array}{c}\text { Fontes sociais } \\
\text { de aquisição }\end{array}$ & $\begin{array}{c}\text { Modos de integração no } \\
\text { trabalho docentes }\end{array}$ \\
\hline $\begin{array}{c}\text { Saberes pessoais dos } \\
\text { professores }\end{array}$ & $\begin{array}{c}\text { A família, o ambiente de } \\
\text { vida, a educação no sentido } \\
\text { lato, etc. }\end{array}$ & $\begin{array}{c}\text { Pela história de vida e pela } \\
\text { socialização primária }\end{array}$ \\
\hline $\begin{array}{c}\text { Saberes provenientes da } \\
\text { formação escolar anterior }\end{array}$ & $\begin{array}{c}\text { A escola primária e } \\
\text { secundária, os estudos } \\
\text { pré-secundários não } \\
\text { especializados, etc. }\end{array}$ & $\begin{array}{c}\text { Pela formação e pela socia- } \\
\text { lização pré-profissionais }\end{array}$ \\
\hline $\begin{array}{c}\text { Saberes provenientes da } \\
\text { formação profissional para } \\
\text { o magistério }\end{array}$ & $\begin{array}{c}\text { Os estabelecimentos de for- } \\
\text { mação de professores, os } \\
\text { estágios, os cursos de reci- } \\
\text { clagem, etc. }\end{array}$ & $\begin{array}{c}\text { Pela formação e pela socia- } \\
\text { lização profissionais nas } \\
\text { instituições de formação de } \\
\text { professores. }\end{array}$ \\
\hline $\begin{array}{c}\text { Saberes provenientes dos } \\
\text { programas e livros didáticos } \\
\text { usados no trabalho }\end{array}$ & $\begin{array}{c}\text { A utilização das "ferramen- } \\
\text { tas" dos professores: pro- } \\
\text { gramas, livros didáticos, ca- } \\
\text { dernos de exercícios, fichas, } \\
\text { etc. }\end{array}$ & $\begin{array}{c}\text { Pela utilização das "ferra- } \\
\text { mentas" de trabalho, sua } \\
\text { adaptação às tarefas. }\end{array}$ \\
\hline $\begin{array}{c}\text { Saberes provenientes de sua } \\
\text { própria experiência na pro- } \\
\text { fissão, na sala de aula e na } \\
\text { escola }\end{array}$ & $\begin{array}{c}\text { A prática do ofício na es- } \\
\text { cola e na sala de aula, a ex- } \\
\text { periência dos pares, etc. }\end{array}$ & $\begin{array}{c}\text { Pela prática do trabalho e } \\
\text { pela socialização profissio- } \\
\text { nal. }\end{array}$ \\
\hline
\end{tabular}

Fonte: TARDIF, Maurice. Saberes docentes e formação profissional., 2004, p. 63.

Os saberes apresentados estão diretamente relacionados à utilização destes no contexto da docência e da sala de aula. O quadro permite observar a natureza social do saber docente, ou seja, compreender que os saberes do professor são provenientes das relações sociais nas quais o professor está inserido dentro e fora da escola, antes ou depois do início de sua carreira, sendo "impossível identificar imediatamente suas origens" (TARDIF, 2004, p. 64).

Os saberes são base para o ensino e relacionam-se com a unidade teórica que fundamenta o saber-fazer, suas atitudes e intenções, que significa que os saberes possuem uma coerência pragmática e biográfica. Não são padronizados e podem não fornece soluções imediatas e prontas para os problemas que acontecem. Além disso, o professor é capaz de 
agir pautado nos juízos normativos provenientes de tradições pedagógicas, escolares e profissionais durante a ação cotidiana (TARDIF, 2004).

Os saberes fundamentam o saber-ensinar, atribuindo-os como existenciais, sociais e pragmáticos. Para o autor, “compreender os saberes dos professores é compreender, portanto, sua evolução e suas transformações e sedimentações sucessivas ao longo da história de vida e da carreira, história e carreira essas que remetem a várias camadas de socialização e de recomeços" (TARDIF, 2004, p. 106).

Assim, é relevante considerar que a formação profissional está diretamente ligada à inserção do professor no mundo ao qual pertence, mediante as relações se dão no mundo, com o mundo e pelo mundo, desta forma, torna-se possível a capacidade de refletir sobre a realidade, a fim de levantar hipóteses e procurar soluções, transformando-a por meio de seu trabalho e de uma consciência intransitiva (FREIRE, 1999a).

Por meio da práxis ${ }^{8}$, é possível ter a possibilidade de mudança da realidade, onde a pedagogia do oprimido que sustenta essa relação entre opressor-oprimido seja destituída em função da pedagogia da liberdade. O primeiro passo é a compressão crítica de se identificar como oprimido, em busca de uma transformação de si e do mundo circundante. Uma vez transformada a realidade opressora, por meio de ações profundas, a pedagogia assume um processo permanente de libertação (FREIRE, 1999b).

Assim, a EJA se constitui como uma nova ou outra possibilidade de acesso ao direito à educação escolar, dentro de uma estrutura pedagógica e organizacional própria, que garante a conclusão do ensino fundamental e/ou ensino médio, considerando as características dos estudantes, seus interesses, suas condições de vida e de trabalho, mediante cursos próprios e exames nacionais.

\footnotetext{
8 O conceito práxis é trabalhado por Freire (1999b), a partir da relação opressor-oprimido, quando o oprimido se percebe nessa relação e engajam-se "na luta organizada por libertação", não somente em nível intelectual, mas por meio de ação associada à reflexão, para aconteça a práxis. Para que exista a autêntica práxis, faz-se necessária a ação resultante da reflexão crítica, "nesse sentido a práxis constitui-se a razão nova da consciência do oprimido" e a revolução encontre viabilidade fora da consciência oprimida (FREIRE, 1999b, p. 52-53).
} 


\section{Letramento no contexto heterogêneo da EJA}

Destoante da lógica da educação "bancária” que cria ingênuos espectadores ajustados ao mundo em que vivem, a domesticação é substituída pela consciência e a educação se torna problematizadora, tornando o educando agente de sua aprendizagem à medida em que domina as técnicas da leitura e da escrita em termos conscientes, ou seja, "é entender o que se lê e escrever o que se entende" (FREIRE, 1999a). Assim, Street (2015) também critica a concepção "bancária" de educação e sugere que os letramentos sejam trazidos para a agenda política, destoando a forma de tratar os "analfabetos" como "social e culturalmente nocivos" precisando ser erradicados. A partir da abordagem etnográfica do estudo do letramento, Street propõe dois modelos de letramento: o autônomo e o ideológico.

O modelo autônomo de letramento trata "o letramento como uma variável independente, supostamente desvinculada de seu contexto social” (STREET, 2015. p. 91), objetivando competências "neutras". A construção e a interiorização deste modelo distancia a língua e os sujeitos, tanto o professor quanto os estudantes, assim como, os processos sociais da leitura e da escrita são associados exclusivamente às noções educacionais em detrimento dos vários usos e significados do letramento. Além disso, para este modelo, a linguagem estrita assumem status superior a linguagem oral (STREET, 2015).

O modelo ideológico de letramento ressalta o "processo de socialização na construção do significado do letramento” (STREET, 2015, p. 44), e traz à tona a preocupação de como se dá o processo nas instituições sociais. Considera o letramento numa perspectiva transcultural, bem como considera os aspectos não só culturais, mas também de estruturas de poder, distantes da neutralidade e autonomia do letramento frente ao contexto dos usos da linguagem. 
No contexto da Lei de Diretrizes e Bases da Educação Nacional (Lei no 9.394)9 publicada em 1996, que institui a Educação de Jovens e Adultos (EJA) como uma modalidade de ensino que tem como objetivo assegurar gratuitamente o direito social à educação aos que não tiveram acesso aos estudos na idade regular ou que não o concluíram em oportunidades educacionais apropriadas, discutir qual modelo se encontra vigente nas práticas docentes parece ser uma contínua necessidade. Isso porque os estudantes que procuram a EJA, partem do desejo de aprender a ler e escrever, seja porque não tiveram oportunidade de estar na escola ou por situações ligadas a exclusão do processo educativo, o que requer uma compreensão mais profunda da linguagem, do processo de ensino-aprendizagem, visando observar se são mantidos padrões mecânicos e burocráticos de preenchimento de mentes com frases, palavras, silabas e letras (FREIRE, 2006), em lugar de uma abordagem de letramento como prática social trazida por Street (2015).

Parte desse público, constituído por adultos e idosos, é considerado produto do fracasso do sistema escolar, e, muitas vezes, já está inserido no mundo do trabalho e nas relações interpessoais, por isso costuma manifestar anseios diferentes, normalmente ligados à formação profissional, visando à ascensão profissional (OLIVEIRA, 2004, 2005). Por outro lado, o jovem atendido na EJA está mais ligado ao mundo urbano e tecnológico, e possui mais chances de concluir os estudos (OLIVEIRA, 2004, 2005), apesar de estar submetido à necessidade de ter que abandonar a escola para trabalhar, o que pode levá-lo a se manter com baixa escolaridade e ter dificuldades em conseguir melhores posições profissionais, ocasionando o aprisionamento ao trabalho informal e aos subempregos (NAIFF; NAIFF, 2008).

Acrescenta-se ainda, um novo público, adolescentes a partir dos quinze anos de idade $^{10}$. Desta forma, o público se ampliou, pois passou a acolher um outro público, a partir 
das Diretrizes Curriculares Nacionais Gerais da Educação Básica que avaliam a necessidade de oportunizar a educação escolar independente d idade, com o intuito de garantir o direito social à educação assegurado pela Constituição de 1988 (BRASIL, 2013).

A alteração da idade compatibilizou uma necessidade de adequação da LDB, em respeito aos direitos estabelecidos pelo Estatuto da Criança e Adolescente (ECA) ${ }^{11}$, por meio de o movimento de juvenilização ou mesmo um adolescer da EJA. "[...] É como se o adolescente e o jovem dessa faixa etária ficasse em uma espécie de não-lugar (atopia) que, associado a outros condicionantes sociais, poderia ser aproveitado por correntes marginais fora do pacto social" (BRASIL, 2013, p. 331).

Desta feita, segundo Oliveira (2005, p. 82), a escola se torna “[...] um local de confronto de culturas [...] e, como qualquer situação de interação social, um local de encontro de singularidades", o que exige do professor saber articular diferenças decorrentes das características psicossociais de cada faixa etária, em “[...] um processo de constante transformação e de geração de singularidades" (OLIVEIRA, 2005, p. 82).

Para favorecer o aprendizado dentro desse contexto, estratégias precisam ser pensadas para auxiliar aqueles que estão em processo inicial nas aprendizagens, como ações de valorização voltada à autonomia, principalmente por aqueles que já conseguem ler ou escrever em um nível mais avançado, para não ocasionar o desestímulo, o que poderia levar a evasão. Esse esforço nos remete ao que Oliveira (2005, p. 64) apresenta na propositiva da “adequação da escola a para um grupo que não é o 'alvo original' da instituição".

mínima para ingresso nos cursos de EJA; idade mínima e certificação nos exames de EJA, ficando definido no art. $5^{\circ}$ que será considerada idade mínima para os cursos de EJA e para a realização de exames de conclusão de EJA do Ensino Fundamental a de 15 (quinze) anos completos.

${ }^{11}$ O ECA, Lei No. 8.069, de 13 de julho de 1990, dispõe sobre o ECA e dá outras providências. Garante no Capítulo IV o direito à educação, visando o pleno desenvolvimento, preparo para o exercício da cidadania e qualificação para o trabalho e prevê o dever do Estado, além disso, no artigo 100 apresenta as medidas específicas de proteção garantindo as necessidades pedagógicas da criança e do adolescente, preferindo-se aquelas que visem ao fortalecimento dos vínculos familiares e comunitários. 
Diante de tamanha complexidade, a formação exigida para o professor que atua na educação básica ${ }^{12}$, particularmente no segmento da EJA, não parece abarcar os pressupostos teóricos e metodológicos exigidos para compreender as diferentes aprendizagens em ambiente tão heterogêneo como o da EJA.

\section{Material didático da EJA}

$\mathrm{Na}$ pesquisa em curso, as falas da professora entrevistada confirmam uma formação em curso superior completo, em Pedagogia, e a frequência em curso de pós-graduação em nível de especialização (lato sensu), em alfabetização e letramento.

Durante a licenciatura, a docente teve o contato com a temática de jovens e adultos, entretanto, salienta que "[...] foi muito restrito... foram poucas aulas... [..] mas foi coisa bem rápida". Em se tratando das diferentes aprendizagens com jovens, adultos e idosos, "lembro que a gente trabalhou... mas coisa assim... bem pouco mesmo... [...]tive sim... mas foi bem pouco... [...] a gente passa naquela correria". Admite que atua como docente nas turmas de EJA "tem um tempo bom... tem na faixa de quase vinte anos", e seus saberes foram adquiridos "mais em sala de aula... vou te falar..." por meio de sua experiência ao longo desses anos.

É notável que essa relação de temporariedade (tempo-trabalho-aprendizagens) de atuação no trabalho educacional revelam o acúmulo de experiência e conhecimentos, por meio de saberes provenientes de sua própria experiência na profissão, assim como preconizada Tardif (2004). As lacunas deixadas durante a formação inicial são construídas durante a pratica do trabalho profissional do magistério em sala de aula.

Entretanto, quando questionada sobre o trabalho voltado aos adolescentes e jovens na EJA demonstra novamente que os saberes experienciais (TARDIF, 2004), resultantes do

12 A LDB (Lei no 9.394/96) traz em seu texto, no artigo 62, a definição da formação exigida ao professora da educação básica: “A formação de docentes para atuar na educação básica far-se-á em nível superior, em curso de licenciatura plena, admitida, como formação mínima para o exercício do magistério na educação infantil e nos cinco primeiros anos do ensino fundamental, a oferecida em nível médio, na modalidade normal". 
exercício da atividade profissional na pratica docente vivenciada em outros momentos anteriores, norteiam o trabalho docente ao afirmar que "esse trabalho direcionado ao perfil dos adolescentes... [...]é complicado... na realidade eu já tive porque trabalhei com fluxo...aquela distorção série e idade... a gente trabalhava naquela época com muito adolescente... [...]".

Retrata ainda em seu relato que "nós tivemos formação... mas foram pouquíssimas...”, ou seja, a SEDUC oportunizava momentos de formação continuada por meio de “encontros que a gente tinha antigamente... [...]uma sexta ou um sábado... entendeu... mas parou de fazer... não sei se por questões financeiras... já tem um tempinho bom”, e, por vezes, essas formações estavam ligadas a questões relativas "ao trabalho... mais experiência... mais voltada pra realidade...". O que infere aos saberes ligados a formação profissional para o magistério (TARDIF, 2004), relativos a contribuição dada pelos cursos de formação continuada que auxiliam a professora em seu trabalho junto ao ensino da EJA.

Sobre o conhecimento acerca do letramento, sua resposta reforça que a formação inicial e a continuada são necessárias para a formação do professor, pois coloca os saberes da formação profissional (TARDIF, 2004): “eu estudei... agora pouco... no curso de pedagogia... nas formações sempre fala", remetendo a formação como processo contínuo para o magistério.

Salienta também que não foi preparada para trabalhar com o LD, "de jeito nenhum", nem pela secretaria nem pela própria escola, reafirmando que alguns conhecimento pertinente à pratica educativa é negligenciada “a gente não teve essa formação". Entretanto, o conhecimento referente aos saberes provenientes dos programas e livros didáticos (TARDIF, 2004), são necessário e, sobretudo, levaram a professora a uma busca individual e curiosa de conhecer, como no caso do manual do LD para o professor, "a gente tem... eu sempre dou uma olhadinha... [...] mas a gente não teve essa formação... a gente está sempre lendo... pra vê se...” Desta feita, observa-se a aquisição deste saber mediante a utilização das “ferramentas" de trabalho e suas adaptações para cotidiano do trabalho docente. 
Constata-se ainda nos depoimentos que o pouco contato com conhecimentos sobre a educação de jovens e adultos durante a formação inicial, bem como, a formação continuada também não faz acréscimos, a professora consolida sua prática a partir dos saberes experiências adquiridos ao longo de seus dezessete anos de magistério na EJA, mas demonstra ter clareza que faz necessário buscar novos saberes: "a gente quer parar e estudar... e está faltando esse tempo... eu estou sentindo essa dificuldade... de coisa do estudar...entendeu... a noite é corrida... é muito rápida... o que acontece é que a noite... não é valorizada... não é valorizada...", mesmo diante do reconhecimento da desvalorização destinada a EJA, não desiste em buscar saberes necessários a sua formação docente.

Ao reunir as colocações da professora foi possível caracterizar o grupo de estudantes, a partir da variação de faixa etária e das diferentes aprendizagens. Trata-se de uma turma composta por estudantes com variada etária, de 14 (quatorze) a 85 (oitenta e cinco) anos de idade, o que anuncia a ampliação do público atendido pela EJA, refletindo a heterogeneidade da turma referente às diferentes aprendizagens ocasionada pela incidência de adolescentes, jovens, adultos e idosos ${ }^{13}$.

A heterogeneidade do público atendido justifica as diferentes características psicossociais da variação etária, também aparece como fator importante de incomodo de alguns estudantes da turma, sendo a presença dos adolescentes um fator de incomodo aos idosos, “até a voz dos adolescentes incomodam eles.... até a conversa... as gírias... [...] principalmente (por)que os idosos da gente... os mais velhos... são muito sensíveis... até um palavrão é uma coisa do outro mundo".

Outro aspecto importante diz respeito aos diferentes níveis do processo de aquisição da leitura e da escrita apresentados pelos estudantes, “eu tenho aluno na fase I que já sabe ler... [...] e tenho alunos que não sabem ler... [...] a maioria não sabe ler...”. Assim, a maioria não demonstra o domínio das técnicas da leitura e da escrita, desses "todos são

13 De acordo com o Estatuto da Juventude (2013) que dispõe sobre os direitos dos jovens, os princípios e diretrizes das políticas públicas de juventude e o Sistema Nacional de Juventude - SINAJUVE, são consideradas jovens as pessoas com idade entre 15 (quinze) e 29 (vinte e nove) anos de idade. 
copistas... mas tem dificuldade de escrever espontâneo", destarte todos confessam experiência escolar, apesar de alguns relatarem que há anos não a frequentam. Os estudantes, que iniciam o ano e apresentam o domínio da leitura, são provocados a fazer uma "prova de amparo", com o intuito da reclassificação e remanejamento para outra turma mais adequada ao seu nível de aprendizagem.

Assim, foram planejadas estratégias para facilitar o aprendizado dos estudantes de diferentes faixas etárias, estimulando o trabalho coletivo: “aí o que é que eu faço... eu acabo tentando... com que os adolescentes trabalhem junto com eles [...] você sabe... ajude ele... [...] ajude ele a fazer essa atividade... [...] eu sempre coloco aquele que sabe mais". Durante as atividades "tento unir eles... [...] quem está mais próximo um do outro... [...] eu não separo não... [...] o que define é a proximidade mesmo...”. Nesse sentido, a docente optou pelo trabalho com um texto instrucional, receita culinária, e apresentou os motivos para essa escolha e a pertinência para fase I, tendo em vista os documentos de âmbito nacional e municipal que norteiam o exercício da profissão.

Nas respostas às indagações, a professora descreve que no planejamento das aulas, que ocorre semanalmente com o auxílio da coordenadora pedagógica, há trocas relevantes entre os professores, com apoio nas competências por área de conhecimento, que acabam favorecendo definir a composição do Diário de Classe.

Os textos instrucionais compõem as temáticas estudadas em seis dias de aulas de língua portuguesa, totalizando 12 horas/aula. Essa escolha justifica-se devido à falta de alimentação escolar na escola por quase um mês e o interesse dos estudantes por receitas: "eles gostam muito de receitas... eles gostam muito... [...] cada um vai dar uma ideia", por isso a professora escolheu trabalhar com as receitas culinárias na turma do primeiro segmento da EJA. Na semana planejada, foram definidos os objetivos e as atividades a serem desenvolvidas nas aulas, conforme observa-se no Quadro II, que se segue: 
Quadro II - Planejamento das aulas.

\begin{tabular}{|c|c|c|c|}
\hline & Objetivos & Estratégias & Material didático \\
\hline $1^{\circ}$. Dia & $\begin{array}{l}\text { Reconhecer o gênero } \\
\text { textual receita culiná- } \\
\text { ria } \\
\text { Apresentar o gênero } \\
\text { receita culinária }\end{array}$ & $\begin{array}{l}\text {-Lanche coletivo com bolo } \\
\text {-Conversa sobre a receita: estrutura do } \\
\text { texto, vocabulário, ingredientes, medidas } \\
\text { e alimentação saudável } \\
\text { - Leitura coletiva e individual da receita } \\
\text { - Reescrita do texto no caderno, obser- } \\
\text { vando a estrutura do texto } \\
\text { - Trabalho com algumas palavras do texto } \\
\text { (número de sílabas e letras) }\end{array}$ & $\begin{array}{l}\text { Atividade impressa } \\
\text { (Figura 3) }\end{array}$ \\
\hline $2^{\circ}$. Dia & $\begin{array}{l}\text { Compreender a estru- } \\
\text { tura e a função do } \\
\text { texto instrucional: re- } \\
\text { ceita, analisando a di- } \\
\text { ferença entre receita } \\
\text { falada e receita es- } \\
\text { crita. }\end{array}$ & $\begin{array}{l}\text { Trabalhando com a receita "Bolo sim- } \\
\text { ples" } \\
\text {-Leitura e dobro das medidas dos ingredi- } \\
\text { entes } \\
\text {-Medidas e preços dos ingredientes } \\
\text {-Unidades de medidas, título, partes da re- } \\
\text { ceita e vocabulário. }\end{array}$ & Atividade impressa \\
\hline $3^{\circ}$. Dia & $\begin{array}{l}\text { Desenvolver habili- } \\
\text { dade de leitura e es- } \\
\text { crita }\end{array}$ & $\begin{array}{l}\text {-Leitura da receita } \\
\text {-Texto lacunado, completar as palavras } \\
\text { que faltam } \\
\text {-Ditado: circular as palavras ditadas pela } \\
\text { professora: bolo, ovos, margarina, fer- } \\
\text { mento, açúcar, leite, trigo, xicaras, colhe- } \\
\text { res, forma. } \\
\text {-Desenho das palavras ditadas }\end{array}$ & $\begin{array}{l}\text { Atividade impressa } \\
\text { (Figura 4) }\end{array}$ \\
\hline $4^{\circ}$. Dia & $\begin{array}{l}\text { Refletir sobre o sis- } \\
\text { tema de escrita alfa- } \\
\text { bético }\end{array}$ & $\begin{array}{l}\text {-Caça-palavras com palavras do texto } \\
\text { "Bolo simples" } \\
\text {-Ditado das palavras do caça palavras } \\
\text {-Organizar as palavras em ordem alfabé- } \\
\text { tica, trabalhando a letra inicial } \\
\text {-Produção (coletiva)de frases usando as } \\
\text { palavras citadas }\end{array}$ & $\begin{array}{l}\text { Atividade impressa } \\
\text { Atividade na lousa } \\
\text { Atividade no ca- } \\
\text { derno }\end{array}$ \\
\hline $5^{\circ}$. Dia & $\begin{array}{l}\text { Localizar as informa- } \\
\text { ções no texto, avan- } \\
\text { çando no processo da } \\
\text { leitura e escrita }\end{array}$ & $\begin{array}{l}\text {-Leitura das frases da cruzadinha } \\
\text {-Preencher a cruzadinha, buscando as res- } \\
\text { postas na receita } \\
\text {-Produção coletiva de listas: } \\
\text { - alimentos doces } \\
\text { - alimentos salgados } \\
\text { - bebidas }\end{array}$ & $\begin{array}{l}\text { Atividade impressa } \\
\text { (Figura 5) }\end{array}$ \\
\hline $6^{\circ}$. Dia & $\begin{array}{l}\text { Produzir uma receita, } \\
\text { observando a estru- } \\
\text { tura textual }\end{array}$ & $\begin{array}{l}\text {-Formação de palavras, usando letras tra- } \\
\text { balhadas na receita. } \\
\text {-Produção coletiva de uma nova receita, } \\
\text { utilizando os ingredientes do "Bolo sim- } \\
\text { ples" } \\
\text {-Trabalhar as famílias silábicas da palavra } \\
\text { BOLO pesquisando as palavras no dicio- } \\
\text { nário }\end{array}$ & $\begin{array}{l}\text { Atividade na lousa } \\
\text { Atividade no ca- } \\
\text { derno }\end{array}$ \\
\hline
\end{tabular}

Fonte: Escola, Ilhéus/BA, 2019. 
O tipo de texto instrucional trabalhado nas aulas, descritas no quadro II, está previsto na Proposta Nacional Curricular do $1^{\circ}$ segmento da EJA (2001) ${ }^{14}$ dentre o trabalho com a linguagem escrita para as turmas iniciantes como forma de atender o objetivo central da língua portuguesa: "formar bons leitores e produtores de textos, que saibam apreciar suas qualidades, encontrar e compreender informações escritas, expressar-se de forma clara e adequada à intenção comunicativa” (BRASIL, 2001 p.55), tendo em vista o aperfeiçoamento da comunicação e o aprendizado da leitura e da escrita, por meio da seleção de textos significativos e interesses.

Apesar de a Base Nacional Comum Curricular (BNCC) ${ }^{15}$ não traçar diretrizes específicas para a educação de jovens adultos, por conseguinte, a SEDUC construiu o documento norteador do trabalho docente que define as competências, os objetos de conhecimento e as habilidades para área do conhecimento língua portuguesa, considerando cinco eixos: oralidade, leitura, produção de texto, conhecimentos linguísticos e gramaticais e educação literária. A partir da Proposta Nacional Curricular da EJA (2001, p. 84-85), identificam-se objetivos didáticos pertinentes ao gênero discursivo selecionado, o que sugere a coerência entre os tipos de textos propostos ao trabalho docente durante a fase I da EJA.

Ao observar o material disponibilizado pela professora, nota-se que as atividades preparadas pela docente contemplam o desenvolvimento da linguagem a partir da conexão entre a linguagem oral e a escrita, por meio da leitura coletiva e individual. A professora participa ativamente desses momentos ao fazer a leitura de textos em voz alta, visando

\footnotetext{
${ }^{14}$ A Proposta Curricular Nacional para a EJA, publicada em 2001, voltada apenas aos anos iniciais do ensino fundamental, o chamado primeiro segmento. Em 2002, foi publicada uma proposta voltada ao segundo segmento, correspondente aos anos finais da etapa. As Diretrizes Curriculares Nacionais para a modalidade foram publicadas em 2000, por meio do parecer no 11 do CNE, cujo relator foi Carlos Roberto Jamil Cury.

${ }^{15}$ A Base Nacional Comum Curricular (BNCC) é um documento normativo que define orgânico e progressivamente as aprendizagens essenciais que todos os alunos devem desenvolver ao longo da Educação Básica, assegurando seus direitos de aprendizagem e desenvolvimento, conforme preceitua o Plano Nacional de Educação (PNE). Integra a política nacional da Educação Básica que pretende contribuir para o alinhamento de outras políticas e ações federais, estaduais e municipais, referentes à formação de professores, à avaliação, à elaboração de conteúdos educacionais e aos critérios para a oferta de infraestrutura adequada para o pleno desenvolvimento da educação (BNCC, 2017).
} 
desenvolver a capacidade de escuta dos estudantes, bem como ampliar a percepção deles, como uma preparação para exercícios da pronúncia, da entonação e da dicção, assumidos como necessários para o bom entendimento da leitura, além de estimular a desinibição em situações públicas.

A Figura 1, a seguir, ao apresentar o gênero receita, "Bolo simples", reúne informações essenciais para que o texto esteja completo e possa ser utilizado no primeiro dia da sequência de atividades planejada pela professora. A atividade foi impressa e entregue a cada um para que fosse possível trabalhar os dois tipos de informações básicas: quais produtos utilizar (lista de ingredientes) e como usá-los na elaboração de um prato (descrição das etapas do preparo). Algumas informações complementares, como o tempo de preparo e o número de pessoas que servem, não estão presentes, porém consta a linguagem característica própria do gênero, o que permite aos estudantes se familiarizar com os numerais, os verbos de ação no imperativo e alguns tipos medida. Isso é reconhecido como importante por proporcionar o acesso às diferentes classes gramaticais, contudo a atividade propõe um trabalho restrito área da matemática, por solicitar apenas a alteração da quantidade prevista inicialmente.

Figura 1 - Atividade impressa do $1^{\circ}$. Dia.

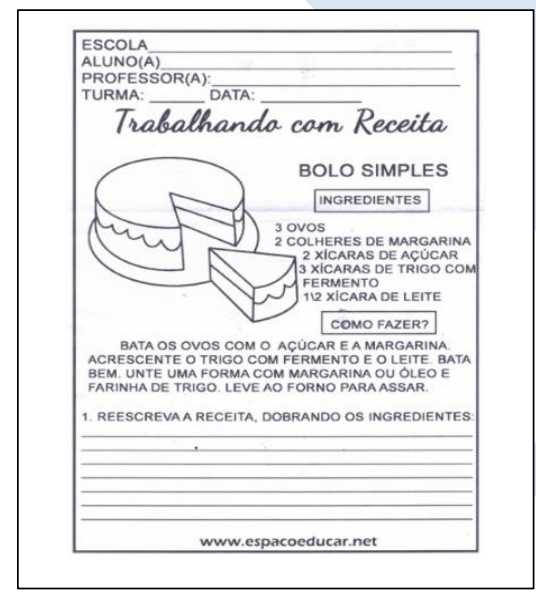

Fonte: Escola, Ilhéus/BA, 2019. 
Como se viu no quadro II, nos cinco dias de trabalho, houve a exploração das informações relativas à receita que, embora faça parte do cotidiano dos estudantes, estão restritas ao âmbito do sistema linguístico, configurando um alinhamento ao modelo autônomo de letramento, em que são trabalhadas competências "neutras", desvinculadas do contexto social, reafirmando o distanciamento entre a língua e os sujeitos, apartados do contexto ao qual cada um dos sujeitos está inserido, limitando-se a práticas de ditado, ao uso do dicionário e à estrutura do texto instrucional.

Observa-se que no sexto dia, no encerramento das atividades, há uma produção textual coletiva: nova receita, com base nos ingredientes do "Bolo simples". Nessa atividade, volta-se a privilegiar o uso do dicionário, visando à ampliação do vocabulário, uma prática distante dos motivos que suscitam textos desse gênero na sociedade.

Quando se relembra os motivos que justificaram esse estudo, dois pontos foram salientados. O primeiro motivo diz respeito à falta de alimentação escolar, o que poderia remeter ao desenvolvimento do senso crítico dos estudantes e criar instrumentos de resistência frente às carências sociais, pois, por meio da leitura e da escrita, os estudantes poderiam refletir acerca do direito à alimentação escolar e das providências necessárias para regularização a situação. Além disso, a temática também oportunizaria a abertura a novos conhecimentos sobre a alimentação saudável e a promoção da saúde, temáticas que dependem da linguagem oral e escrita. O segundo motivo está associado aos interesses dos estudantes em estudar as receitas culinárias, por permitir trocas de experiências e conhecimentos já acumulados em suas trajetórias de vidas, e quiçá a partilha de novas receitas e novas formas de preparo. Assim, as práticas de leitura e escrita estariam sendo postas em ação, incentivados pelos próprios interesses dos estudantes.

Durante esse ano letivo de 2019, a professora relata que o livro didático (LD), volume 1 da coleção "EJA Moderna: Educação de Jovens e Adultos", que foi entregue aos estudantes é o mesmo adotado pela rede municipal de Ilhéus no PNLD-EJA do triênio 2014- 
2016 ${ }^{16}$. A não realização do processo de escolha para o próximo triênio 2017-2019 indica descontinuidade do PNLD-EJA. Ressalta-se também que, segundo a professora, o livro escolhido pela escola não foi o mesmo que veio para sua utilização, o que demonstra que apesar de haver um processo democrático de escolha, fatores nem sempre muito claros impõem a homogeneização devido à indução de uma única obra para toda uma rede de ensino, o que acabou por desconfigurar a autonomia pedagógica das escolas e de seus coletivos (MELLO, 2015).

Desse modo, apesar não ter sido mencionado no planejamento das aulas, verificase que orienta o trabalho com textos instrucionais em três momentos do LD. Na página 123, quando aborda a questão cultural por meio dos festejos juninos, encontra-se uma "Receita de pé de moleque”, ao final do livro, na página 202, estão listados os ingredientes de uma receita de brigadeiros. Em outro momento, a receita culinária é parte integrante do capítulo 3, intitulado "Festas, danças e culinária do Brasil". Os textos, "Festas, danças e culinária do Brasil" e "Um Brasil de muitos sabores", nas páginas 147 e 149, respectivamente, antecedem e contextualizam a receita culinária a partir da cultura popular brasileira, por se tratar de um alimento típico, mas as atividades que tratam da receita se restringem à estrutura do texto instrucional, "assume uma perspectiva de inserção do sujeito nas práticas e eventos de letramento", segundo o Guia dos Livros Didáticos do PNLD-EJA (2014, p.76).

A figura 2, a seguir, recupera a "Receita de tapioca" para orientar um trabalho com a leitura e escrita dos educandos a partir de questões encontradas nas páginas 150 e 151, deste mesmo LD.

\footnotetext{
${ }^{16}$ Ressaltamos que o PNLD-EJA passou a adquirir e distribuir obras didáticas destinadas ao primeiro e segundo segmento da EJA, através de uma política nascida quando o Ministério da Educação (MEC) instituiu, em 2007, o Programa Nacional do Livro Didático para a Alfabetização de Jovens e Adultos (PNLA), que foi extinto em 2009 e substituído pelo Programa Nacional do Livro Didático para Educação de Jovens e Adultos (PNLD-EJA), como forma de atender uma demanda da EJA e distribuir o livro didático para as escolas. Esse programa, que existe hoje, é parte de um processo de várias reformulações e reorganização de políticas educacionais ao longo das últimas décadas, iniciado pelo Programa Brasil Alfabetizado (PBA), visando combater o analfabetismo em todas as regiões do país, por meio de investimentos feitos pelo Ministério para a produção de materiais didáticos interdisciplinares e flexíveis (MELLO, 2015).
} 
Figura 2 - Receita de Tapioca e atividades do LD.
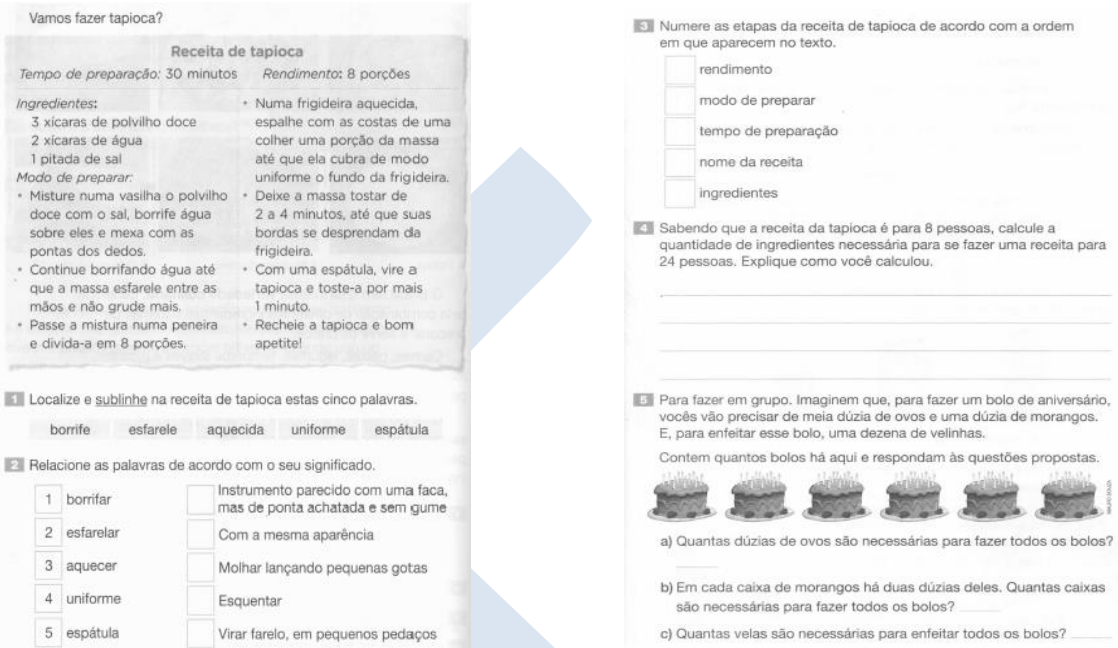

Fonte: EJA Moderna: Educação de Jovens e Adultos, volumes 1, páginas 150 e 151.

Apesar de o Guia dos Livros Didáticos do PNLD-EJA (2014, p. 76) trazer uma avaliação positiva da coleção utilizada: "Os conteúdos apresentados são diversificados e atualizados, com articulações entre o que está sendo estudado e as experiências de vida dos jovens e adultos, com atenção às características de aprendizagem desses estudantes". Contudo, a professora não demonstra gostar em trabalhar o LD, preferindo produzir seu próprio material didático, afirmando que "eu não gosto não... [...] ele se torna restrito... [...] eu prefiro fazer minhas atividades... [...] não sou muito chegada não... [...] eles acham difícil... o livro... essa é a verdade... eles acham o livro difícil [...] eu pouco uso o livro... talvez o preconceito seja até meu... [...] olha o quem no livro... sinônimos... antônimos... a gente trabalha mais alfabetização mesmo". 


\section{Considerações}

Em sínese, compreende-se que as práticas de letramento social na educação de jovens e adultos são viabilizadas pelo processo contínuo de formação de professores, mediante os saberes docentes mobilizados a partir do pluralismo inerente às relações do professor e seus saberes decorrentes da formação profissional e pessoal, além dos saberes disciplinares, curriculares e experienciais, pertinentes da associação entre tempo, trabalho e aprendizagens fomentando assim, a prática docente.

O processo de escolha, elaboração e produção de materiais didáticos estão associados ao alinhamento do modelo de letramento autônomo conectado à prática educativa da professora, com práticas de letramento desvinculadas das práticas sociais. Observa-se que o modelo autônomo segue como o mais recorrente no ambiente escolar, reafirmando os saberes provenientes da formação inicial e continuada, ou mesmo, refletindo as lacunas existentes na formação profissional pela falta de conhecimento sobre o letramento social.

A realidade heterogênea da EJA constatada pela presença de adolescentes, jovens, adultos e idosos e suas diferentes aprendizagens e culturas torna evidente dessa pluralidade no mesmo ambiente escolar. Ao analisar o planejamento das aulas durante os seis dias de trabalho com receitas culinárias, não verificamos estratégias alternativas para atender os diferentes públicos, o trabalho foi igual para todos, porém observou-se a interação proposta no agrupamento de estudantes de diferentes faixas etárias. A falta de domínio dos saberes para lidar com essa realidade dificulta o trabalho e provoca a busca de soluções aos problemas enfrentados por meio de sua própria experiência docente, seja por saberes decorrentes de sua formação escolar anterior ou das experiências vivenciadas dentro da sala de aula ou coletivamente com outros profissionais da escola.

Durante o planejamento das aulas e a elaboração de materiais didáticos, observa-se o uso predominante de atividades impressas, entretanto, faz-se necessário ampliar com outros materiais didáticos, inclusive com a utilização do LD, além de considerar questões referentes ao interesse dos estudantes e suas vivências, como forma de discutir a realidade 
cotidiana dos educandos e tornar as aprendizagens da leitura e da escrita significativas, estimulando o senso críticos dos estudantes, a fim de torná-los conscientes de sua ação no mundo em que vivem e as possibilidades de transformá-lo.

A professora demonstra interesse, dedicação e empenho ao trabalhar com a EJA, no entanto, lacunas na formação inicial e continuada aparecem no entendimento epistemológico do letramento social, no manejo e na elaboração de materiais didáticos, bem como no domínio das aprendizagens do público atendido, considerando a heterogeneidade dos níveis de aprendizagem e variação das faixas etárias. Isso sugere a necessidade de uma formação dos professores eficaz que contemple as especificidades desta realidade educacional, inclusive abordando a inserção no mundo do trabalho.

\section{FORMACIÓN DOCENTE Y LETRACIÓN: UNA REALIDAD VIVENCIADA EN LA EJA}

RESUMEN: Este estudio objetiva discutir la formación de profesores a partir de la utilización de materiales didácticos concordantes con la promoción del letra social en el trabajo pedagógico dentro del aula. Se trata de una investigación social, apoyada en el estudio de caso junto a una escuela pública de Ilhéus / BA, a partir de una entrevista con una profesora de la EJA, orientada al entendimiento de su formación profesional y de los modos de elección, elaboración y utilización del mismo material didáctico. Como aporte teórico, destaca Freire que transita por la educación de jóvenes y adultos en diferentes frentes, tanto en el entendimiento de este ambiente desafiante, como en las cuestiones relacionadas con los saberes necesarios al profesor para una práctica educativa transformadora y emancipadora; Tardif (2004) que aborda los saberes docentes y su relación con la formación profesional implicados en la actividad docente; (2015) que propone los modelos de letramento autónomo e ideológico, con repercusión en las prácticas de letra social para apropiación de la lectura y escritura; y Mello (2015), que trata la producción didáctica de la EJA como prácticas de producción y construcción de saberes en el medio escolar. En síntesis, se discuten algunos análisis de la voz de la docente buscando escrutar la apropiación de saberes que son determinantes para la profesionalización en una práctica didáctico-pedagógica que pueda resignificar las relaciones entre lenguaje / lenguaje entre los sujetos que se encuentran implicados en situaciones sociales pertinentes al público, ambiente de la EJA, a fin de contribuir a la transformación social de los sujetos involucrados en procesos de enseñanza y aprendizaje.

PALABRAS CLAVE: EJA; Formación de profesores; Letración social; Material didáctico. 


\section{REFERENCIAS}

BRASIL. Lei de Diretrizes e Bases da Educaşão Nacional. LDB No. 9394/96. Congresso Nacional. Brasília, DF, 2017.

. Base Nacional Curricular Comum. Ministério da Educação. Brasília: MEC, 2017.

. Guia dos Livros Didáticos do PNLD EJA 2014. Ministério da Educação. Secretaria de Educação Continuada, Alfabetização, Diversidade e Inclusão. Natal: EDUFRN, 2014.

. Estatuto da Juventude. Lei No. 12.852, de 5 de agosto de 2013. Congresso Nacional. Brasília, DF.

Resolução No3, de 15 de junbo de 2010. Ministério da Educação. Conselho Nacional de Educação. Brasília, DF.

. Lei $n^{\circ} 11.738$, de 16 de julho de 2008. Congresso Nacional. Brasília, DF.

. Educação para jovens e adultos: ensino fundamental: proposta curricular - $1^{\circ}$ segmento. Coordenação e texto final de Vera Maria Masagão Ribeiro. São Paulo: Ação Educativa; Brasília: MEC, 2001.

. Estatuto da Criança e do Adolescente. Lei No. 8.069, de 13 de julho de 1990. Congresso Nacional. Brasília, DF.

GARCIA, C. M. A formação de professores: novas perspectivas baseadas na investigação sobre o pensamento do professor. In: NÓVOA, A. Os professores e a sua formação. 3. ed. Lisboa: Nova Enciclopédia, 1997 [1992]. p.51-76.

FREIRE, P. A educação na cidade. 7. ed. São Paulo: Cortez, 2006.

. Educação e mudança. São Paulo: Paz e Terra, 1999a.

- Pedagogia do oprimido. São Paulo: Paz e Terra, 1999b.

. Pedagogia da autonomia: saberes necessários à pratica educativa. São Paulo: Paz e Terra, 1997.

GIL, A. C. Métodos e técnicas de pesquisa social. 6. ed. São Paulo: Atlas, 2008.

ILHÉUS. Diário. Secretaria de Educação. Coordenação da Educação de Jovens e Adultos. Ilhéus: SEDUC, 2019.

MELLO, P. E. D. Programas de materiais didáticos para a EJA no Brasil (1996-2014). Atos de Pesquisa em Educação. Blumenau, v. 10, n. 1, p.80-99, jan/abr. 2015.

MODERNA. Eja Moderna: Educação de Jovens e Adultos. 1. ed. São Paulo Moderna, 2013. 
NAIFF, L. A. M.; NAIFF, D. G. M. Educação de jovens e adultos em uma análise psicossocial: representações e práticas sociais. Psicologia \& Sociedade; n. 20, v. 3, p. 402-407, 2008 .

OLIVEIRA, M. K. Jovens e adultos como sujeitos de conhecimento e aprendizagem. Educação como exercício de diversidade. Brasília: UNESCO, MEC, ANPEd, 2005. p. 61-84

. Ciclos de vida: algumas questões sobre a psicologia do adulto. Educação e Pesquisa, São Paulo, v. 30, n. 2, p. 211-229, maio/2004.

PENNYCOOK, A. A Linguística Aplicada Dos Anos 90: em Defesa de Uma Abordagem Crítica. In: SIGNORINI, I; CAVALCANTI, M. C. Linguística Aplicada e Transdisciplinaridade. Campinas: Mercado de Letras, 2007. p. 21-46.

STREET, B. Letramentos sociais: abordagens críticas do letramento no desenvolvimento, na etnografia e na educação. Trad. Marcos Bagno. São Paulo: Parábola Editorial, 2015.

TARDIF, M. Saberes docentes e formação profissional. 4. ed. Rio de Janeiro: Vozes, 2004.

Recebido em: 01/05/2019.

Aprovado em: 14/07/2019. 